\title{
Highly sensitive voltammetric detection of DNA hybridization in sandwich format using thionine-capped gold nanoparticle/reporter DNA conjugates as signal tags
}

\author{
Xuhui Liu • Rui Zhang $\cdot$ Xiaqing Yuan $\cdot$ Lu Liu • \\ Yiying Zhou • Qiang Gao \\ Published online: 21 December 2013 \\ (C) The Author(s) 2013. This article is published with open access at SpringerLink.com
}

\begin{abstract}
A highly sensitive sandwich DNA detection method based on voltammetric detection of thionine-capped gold nanoparticle (AuNP)/reporter DNA conjugate tags on gold particle-modified screen-printed carbon electrode (SPCE) was developed. The SPCE was modified with gold particle by electrodeposition of gold on SPCE surface. The DNA sensor was prepared by self-assembly of a thiolated DNA probe on gold particle-modified SPCEs. The sandwich-type system was formed by specific recognition of biosensor surface-confined probe DNA to target DNA, followed by attachment of thionine-capped AuNPs/reporter DNA conjugates. The biosensor is very sensitive because of the large number of electroactive thionine molecules in the thioninecapped AuNPs/reporter DNA conjugates. Under optimal conditions, the dynamic detection range of target DNA was from $1.0 \times 10^{-16}$ to $1.0 \times 10^{-14} \mathrm{~mol} \mathrm{~L}^{-1}$, and the detection limit was $0.5 \times 10^{-16} \mathrm{~mol} \mathrm{~L}^{-1}$. The DNA sensor exhibited selectivity against single-base mismatched DNA.
\end{abstract}

Keywords DNA · Sandwich · Thionine · Gold nanoparticles/ reporter DNA conjugates $\cdot$ Screen-printed carbon electrode

\section{Introduction}

High-sensitivity detection of nucleic acids is essential in clinical diagnosis, pathology, and genetics $[1,2]$. Sensitivity of DNA biosensors is usually determined by signal variation amplitude of hybridization event. Increasing efforts have been

X. Liu $\cdot$ R. Zhang $\cdot$ X. Yuan $\cdot$ L. Liu $\cdot$ Y. Zhou $\cdot$ Q. Gao $(\bowtie)$ Key Laboratory of Applied Surface and Colloid Chemistry, Ministry of Education, School of Chemistry and Chemical Engineering, Shaanxi Normal University, Xi'an 710062, China

e-mail: gaoqiang@snnu.edu.cn focused on the improving analysis of DNA by signal amplification to enhance the sensitivity of DNA biosensors [3-5].

Electrochemical method has received considerable attention in the development of DNA biosensors because it is a simple, inexpensive, and sensitive platform [6]. The feasible sensitivity of an electrochemical detection scheme is generally dependent on the amount of electrical charge provided by the labels. Therefore, the sensitivity of detection can be enhanced by increasing the signal elements attached to each oligonucleotide target [7-9]. Gold nanoparticles (AuNPs) have recently drawn great interest in biosensor development because they are biocompatible and inert [10]. AuNPs have been employed to amplify signals by forming a nanoparticle ensemble substrate on electrode, thereby increasing the amount of immobilized probe DNA on the electrode surface [11]. AuNPs are also extensively used as labels because each AuNP can provide thousands of electrochemically detectable elements either by itself [12] or as a carrier for enzymes to produce electroactive materials [13]. Wang et al. used 6ferrocenylhexanethiol to cap the AuNPs to amplify voltammetric detection of DNA hybridization [14]. In this method, AuNPs were used as carrier for electroactive materials. However, streptavidin was needed to functionalize AuNPs, so that 6-ferrocenylhexanethiol-capped AuNPs could bind to biotin-labeled reporter DNA. In these methods, complex detection procedures necessitate a robust and simple signal-amplification approach.

Thionine is a small electroactive molecule [15] that is usually used as an electrochemical indicator for DNA hybridization because it possesses strong interaction with DNA [16]. Nitrogen atoms of the $\mathrm{NH}_{2}$ moieties of thionine bind strongly to AuNP surfaces. Therefore, AuNPs can be used as labels for the accumulation of thionine on the electrode surface $[17,18]$. Through thionine modified AuNPs was prepared and used as tags, the aggregation of AuNPs occurred due to surface charge 
neutralization of cationic thionine molecules and negative citrate-protected AuNPs [19]. Since their introduction in 1996, the use of oligonucleotide-AuNP conjugates (DNAAuNPs) in DNA sensing has been extensively studied [20]. After the modification of AuNPs with oligonucleotides, the AuNP solution is stable even in the presence of $\mathrm{NaCl}$ [21] (Scheme 1).

In this study, we report the preparation of thionine-capped AuNP/reporter DNA conjugates and their application in sandwich-type electrochemical detection of target DNA at low levels. The sandwich-type system is formed by specific recognition of biosensor surface-confined probe DNA to target DNA, followed by successive attachment of thioninecapped AuNPs/reporter DNA conjugates. Fabrication and performance of the DNA sensor are presented.

\section{Experimental}

Chemicals

All oligodeoxynucleotides were purchased from Shanghai Sangon Biological Engineering Technology and Services Co., Ltd. (China). Oligodeoxynucleotide concentration was determined by its molar extinction coefficient at $260 \mathrm{~nm}$ using UV spectrophotometer (UV-2450, Shimadzu Corporation, Japan). The oligonucleotide sequences for both the probes and the targets are shown in Table 1.

Bovine serum albumin (BSA), thionine, 6mercaptohexanol $(\mathrm{MCH})$, and $\mathrm{HAuCl}_{4} \cdot 3 \mathrm{H}_{2} \mathrm{O}$ were purchased
Table 1 DNA probes and their targets

\begin{tabular}{ll}
\hline Name & Sequence $\left(5^{\prime}\right.$ to $\left.3^{\prime}\right)$ \\
\hline Probe DNA & SH- $\left(\mathrm{CH}_{2}\right)_{6}$-GCTGCTCTGGGTCTCAATGG \\
Reporter DNA & SH-[PEG]-TCCCCGGCGCCACTGGCCAC \\
Diblock-DNA & AAAAAAAAAAAAAATT \\
Target DNA & GTGGCCAGTGGCGCCGGGGAGGCAGCCA \\
& TTGAGACCCAGAGCAGC \\
Single mismatch & GTGGCCAGTCGCGCCGGGGAGGCAGCCA \\
\multicolumn{1}{c}{ DNA } & TTGAGACCCAGAGCAGC \\
Noncomplementary & AACCAGTCACATATAAAATTCCATCAGTCG \\
\multicolumn{1}{c}{ DNA } & CTATGGGTCTCTTAG \\
\hline
\end{tabular}

from Sigma-Aldrich. Carbon ink (Electrodag 423SS) was obtained from Acheson Colloids (Japan). Phosphate buffer solution (PBS) consisted of $0.01 \mathrm{M}$ phosphate-buffered saline, $0.1 \mathrm{M} \mathrm{NaCl}$, and $3 \mathrm{mM} \mathrm{KCl}(\mathrm{pH}$ 7.4). Other chemicals and reagents were commercially available and were of analytical grade. Water was obtained from Millipore Milli-Q purification system.

Instrumentation

Cyclic voltammetry (CV) and differential pulse voltammetry (DPV) experiments were performed on a CHI 832 electrochemical workstation (Shanghai, China). All experiments were performed with a conventional three-electrode system using screen-printed carbon electrode (SPCE) as working

Scheme 1 Scheme for sandwich

DNA hybridization detection using thionine-capped AuNP/reporter DNA conjugates as signal tags

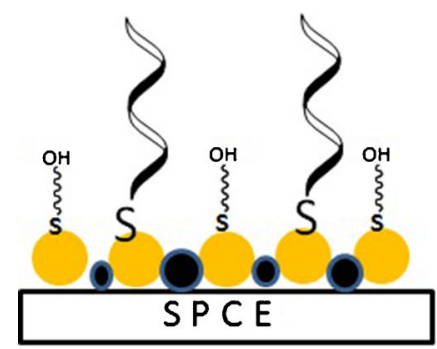

target DNA

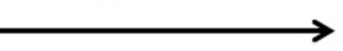

thionine capped AuNP/reporter DNA conjugates

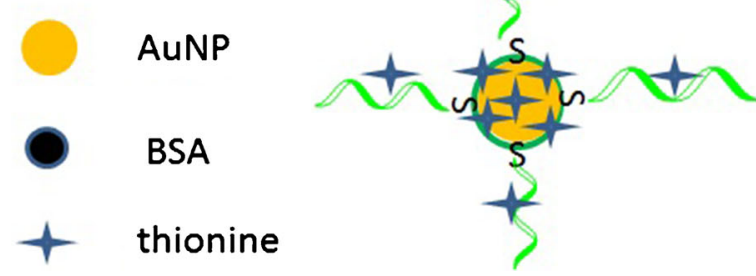

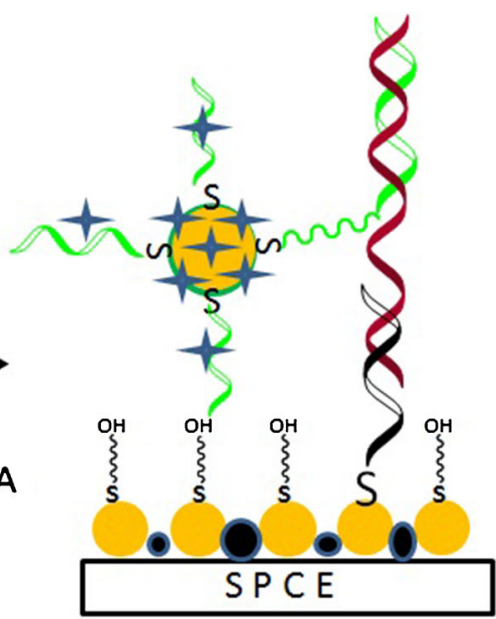

thionine capped AuNP/reporter DNA conjugates 
electrode, a platinum foil as counter electrode, and an $\mathrm{Ag} /$ $\mathrm{AgCl}$ (saturated $\mathrm{KCl}$ ) as reference electrode. All the potentials were presented in terms of $\mathrm{Ag} / \mathrm{AgCl}$ electrode potentials.

UV visible spectra from 200 to $800 \mathrm{~nm}$ were measured using a Shimadzu UV-2450 spectrophotometer. Transmission electron microscopy (TEM) images were obtained using a JEM-2100 microscope with an accelerating voltage of $200 \mathrm{kV}$. Scanning electron microscopy (SEM) was performed using a Quanta 200 (FEI, Philips) apparatus. The acceleration voltage was $20 \mathrm{kV}$.

Synthesis of thionine-capped AuNP/reporter DNA conjugates

AuNPs (13 nm diameter) were prepared by reducing of $\mathrm{HAuCl}_{4}$ with trisodium citrate [22]. Conjugates of reporter DNA-conjugated AuNPs (AuNP/reporter DNA) were synthesized following a published protocol [23, 24]. Briefly, AuNP/reporter DNA conjugates were synthesized by incubating ssDNA, including $1.0 \mu \mathrm{M}$ reporter DNA and $4.0 \mu \mathrm{M}$ diblock-DNA, in $1 \mathrm{~mL}$ AuNP solution (13 nM). The AuNP/reporter DNA conjugates were left for $16 \mathrm{~h}$ and "aged" in salts $(0.1 \mathrm{M} \mathrm{NaCl}$, and $10 \mathrm{mM}$ Tris- $\mathrm{HCl}, \mathrm{pH} 7.0)$ for $24 \mathrm{~h}$. Excess reagents were removed by centrifugation at $15,000 \mathrm{rpm}$ for $30 \mathrm{~min}$. The red precipitate was washed, recentrifuged, and then dispersed in $1 \mathrm{~mL}$ water.

AuNP/reporter DNA conjugate solution $(1 \mathrm{~mL})$ was mixed with $0.05 \mathrm{~mL}$ thionine aqueous solution $(20 \mathrm{mM})$ and stirred effectively for $24 \mathrm{~h}$. The solution was then centrifuged at $15,000 \mathrm{rpm}$ to obtain the precipitate of thionine-capped AuNP/reporter DNA conjugates. Then, the precipitate was washed several times with cold water. The precipitate was redispersed easily in water through sonication. Unbound thionine were removed from the DNA-AuNP solutions by repeated washing and centrifugation.

\section{Immobilization of probe DNA}

SPCE was used as base electrode and the electrodeposition of gold on SPCEs was according to the Ref [25]. Probe DNAs were immobilized on gold particle-modified SPCEs by selfassembly. Briefly, $50 \mu \mathrm{L}$ of $0.5 \mu \mathrm{M}$ probe DNA in PBS

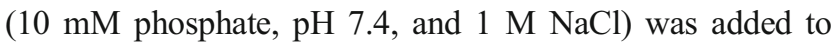
the electrode and incubated overnight at $4{ }^{\circ} \mathrm{C}$. Subsequently, the electrode was washed thrice with PBS, and then $250 \mu \mathrm{L}$ of $50 \mathrm{mM} \mathrm{MCH}$ was added and incubated for $3 \mathrm{~h}$ at room temperature. In the present research, $\mathrm{MCH}$ was used to block the surface of AuNPs through self-assembly to reduce nonspecific binding. Then, the electrode was washed three times with PBS and immersed in PBS containing BSA for $10 \mathrm{~min}$ to block electrode surface. Finally, the electrode was washed once to remove the unbound BSA. The resulting electrode was used as DNA sensor.
Target DNA detection and analytical signal recording

Hybridization was performed by incubating the DNA sensor in a target DNA solution for $30 \mathrm{~min}$. After hybridization, the sensor was washed three times with PBS buffer to remove the physically adsorbed target DNA. Subsequently, the thioninecapped AuNP/reporter DNA conjugate solution was coated onto the resultant electrode surface, and the interaction was kept at room temperature for $30 \mathrm{~min}$ to obtain a sandwich sensing system. Finally, the DNA sensor was again washed with PBS buffer three times to remove unbound thioninecapped AuNP/reporter DNA conjugates.

\section{Results and discussion}

Preparation of thionine-capped AuNP/reporter DNA conjugates

While DNA-AuNPs conjugates typically exploit the wellestablished strong $\mathrm{Au}-\mathrm{S}$ chemistry to self-assemble thiolated oligonucleotides at the surface of AuNPs, it remains challenging to precisely control the orientation and conformation of surface-tethered oligonucleotides and finely tune the hybridization ability [23]. Studies with planar Au substrates have shown that poly adenine (polyA) sequences containing multiple consecutive adenines preferentially adsorb Au with high affinity, even comparable to $\mathrm{Au}-\mathrm{S}$ chemistry. Pei et al. [24] reported a bioconjugation of AuNPs with diblock-DNA containing polyA. The strategy provided a reproducible means to prepare nanoconjugates with well-defined surface density and favorable hybridization ability. Further, unlike thiolated oligonucleotides, diblock oligonucleotides are natural sequences that are essentially free of any modification, hence the synthesis cost is reduced and possible contamination is prevented. Therefore, the diblock-DNA (contains a poly $\mathrm{T}$ and a polyA sequence) was used to decrease the density of reporter DNA on AuNP and improve the hybridization of reporter DNA to target DNA. Formation of thionine-capped AuNP/reporter DNA conjugates was confirmed using UV-Vis spectroscopy and TEM. The spectrum of thionine (curve a) in water exhibits characteristic absorption bands at $598 \mathrm{~nm}$, which is a characteristic absorption feature of its monomeric form (Fig. 1) [26]. Curve $b$ in Fig. 1 is the absorption spectrum of AuNP solution, in which the band at $520 \mathrm{~nm}$ is a characteristic absorption feature of surface plasmon resonance (SPR) of AuNPs. The characteristic absorbance of reporter ssDNA appeared at $260 \mathrm{~nm}$. Two characteristic absorbances (520 and $260 \mathrm{~nm}$ ) were observed on the AuNP-ssDNA conjugation (curve c), which proved that the reporter ssDNA was successfully bound to the surface of AuNPs by the formation of stable $\mathrm{Au}-\mathrm{S}$ bond [27]. Curve $d$ in Fig. 1 is the absorption spectrum of the prepared thionine-capped AuNP/reporter DNA conjugates, 


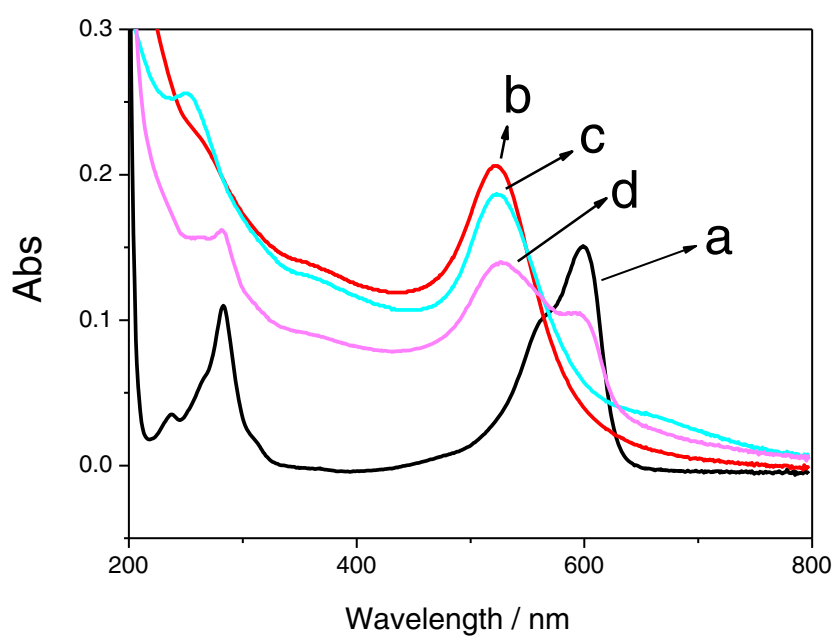

Fig. 1 Absorption spectra. (a) thionine, (b) AuNP, (c) AuNP/reporter DNA conjugates, and $(d)$ thionine-capped AuNP/reporter DNA conjugates

in which three characteristic absorbances (thionine at $598 \mathrm{~nm}$, ssDNA at $260 \mathrm{~nm}$ and AuNP at $520 \mathrm{~nm}$ ) are observed. This finding, clearly indicates the adsorption of thionine on AuNP/reporter DNA conjugates, and that the position of SPR exhibited by AuNPs is not influenced by thionine adsorption.

Uniform dispersion of thionine-capped AuNP/reporter DNA conjugates was further confirmed using TEM. Figure 2 shows the TEM images and the corresponding size distribution histograms of AuNP/reporter DNA conjugates before and after thionine addition. The prepared AuNP/reporter DNA conjugates are almost spherically shaped and separated from
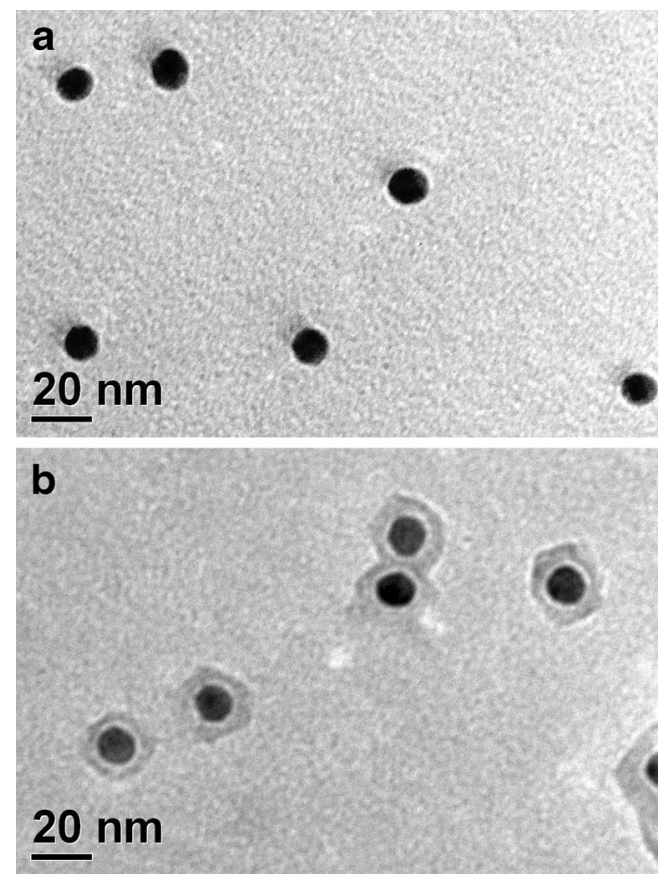

Fig. 2 TEM images of AuNP/reporter DNA conjugates before (a) and after (b) thionine addition one another (Fig. 2a). The AuNP/reporter DNA conjugates still exhibit similar particle sizes (approximately $13 \mathrm{~nm}$ ) without obvious aggregation after thionine addition, indicating that adsorption of DNA on AuNPs surface can protect AuNPs from aggregation even with the presence of thionine (Fig. 2b).

\section{Detection of target DNA}

The morphology of the Au particles modified SPCEs were characterized by SEM. Figure 3 displays the typical SEM images of a bare SPCE (A) and an SPCE after Au electrodeposition (B). A rough and jagged structure with randomly distributed carbon particles was observed for the bare SPCEs (Fig. 3a). After the electrodeposition of Au on the SPCEs, the surfaces of the electrodes were mostly covered with homogeneous particles (Fig. 3b), indicates that Au particles have been electrodeposited on the SPCE surface for the immobilization of probe DNA.

Figure 4 shows the CVs of the DNA sensor before and after hybridization to target DNA as well as the formation of a sandwich complex. No redox current response was observed in the absence of target DNA (curve a). After hybridization to
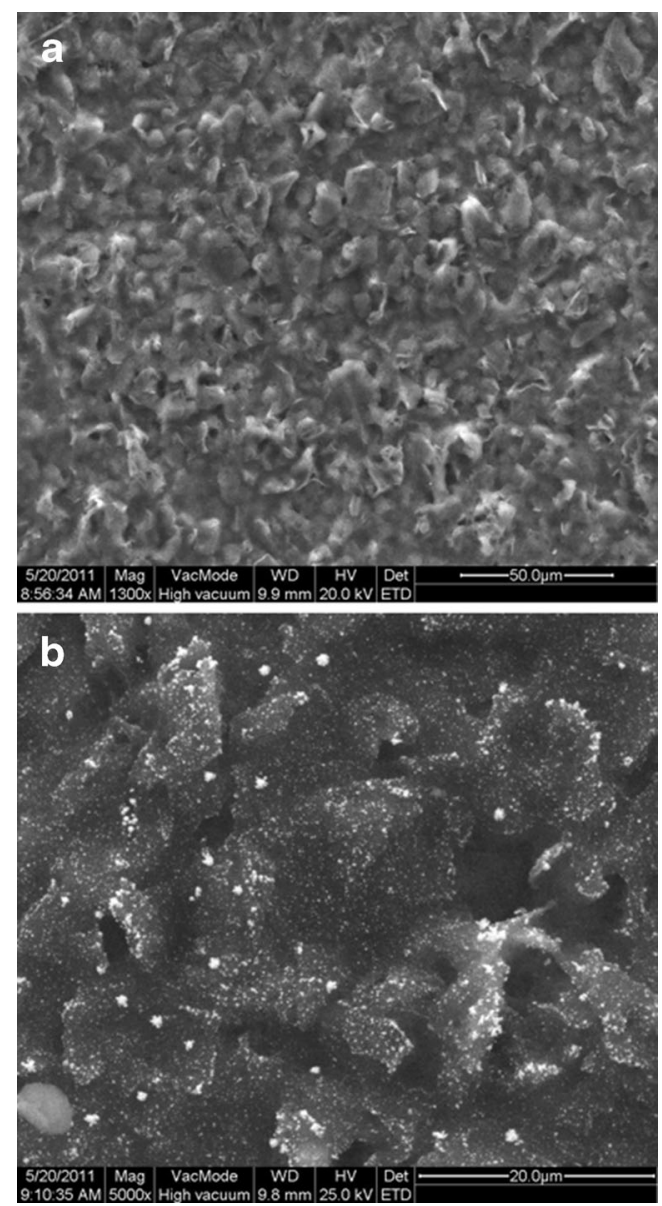

Fig. 3 SEM images of SPCE before (a) and after (b) electrochemical Au deposition 


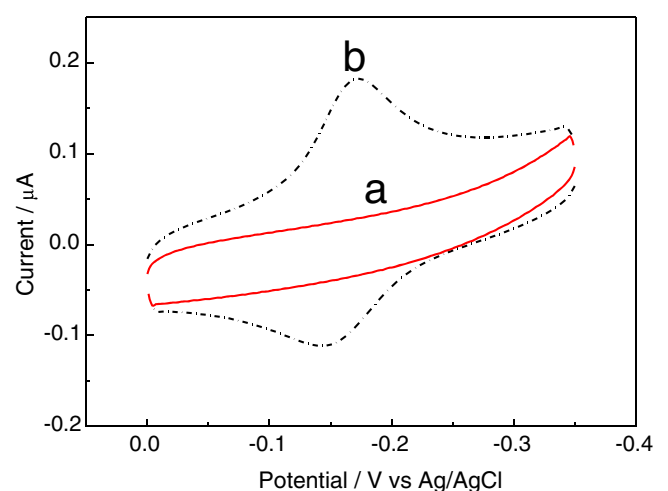

Fig. 4 Cyclic voltammograms of DNA sensors before $(a)$ and after $(b)$ hybridization to target DNA and formation of sandwich complex

the target DNA (100 fM) and formation of a sandwich complex, a well-defined CV corresponding to thionine was observed at formal potential of $-0.17 \mathrm{~V}$ versus $\mathrm{Ag} / \mathrm{AgCl}$. When the sweep rate was $20 \mathrm{mV} / \mathrm{s}$, thionine showed an oxidation peak at $-0.15 \mathrm{~V}$ and a reduction peak at $-0.19 \mathrm{~V}$, the peak-topeak separation was found to be about $40 \mathrm{mV}$. These results suggest that the thionine-capped AuNP/reporter DNA conjugates were bound to the DNA sensors after hybridization of target DNA to the immobilized probe DNA and reporter DNA.

Figure 5 shows the DPV response of the DNA sensor for the target DNA with an increase in concentration from 0.1 to $500 \mathrm{fM}$. Well-defined DPV curves were observed. The currents were proportional to the target DNA concentrations. The DPV response was linearly related to the target concentration across a range of 0.1 to $100 \mathrm{fM}$. The regression equation was I

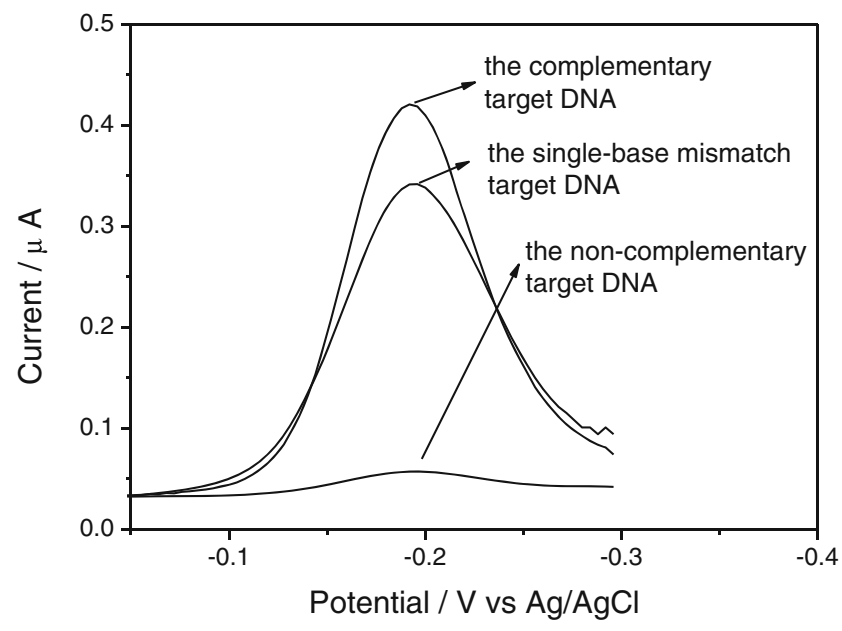

Fig. 6 DPV responses of DNA sensor to the complementary target DNA, single-base mismatch target DNA, and noncomplementary target DNA

$(\mu \mathrm{A})=0.27+0.17 \mathrm{lg}$ [target DNA] $(\mathrm{fM})$, and the correlation coefficient was 0.993 . The detection limit was $0.05 \mathrm{fM}$ $(S / N=3)$, lower than $0.5 \mathrm{fM}$ for enzyme-based electrochemical DNA sensors [28] but similar to the lowest values obtained in bioassays based on multifunctional encoded DNA-Au bio bar code amplification [29]. Hence, a method of improving sensitivity and lowering the detection limit is obtained.

Measurement reproducibility, which is estimated as the relative standard deviation of three measurements with different electrodes at different concentrations, was investigated. Results are shown in Fig. 5 and its inset. For a DNA concentration of $100 \mathrm{fM}$, the relative standard deviation for six
Fig. 5 DPV responses of the DNA sensor to different concentrations of target DNA. Concentrations of target DNA (bottom to top): 0.1, 0.3, 1.0, 5.0, $10,50,100$, and $500 \mathrm{fM}$. Inset linear detection range of 0.1 to $100 \mathrm{fM}$

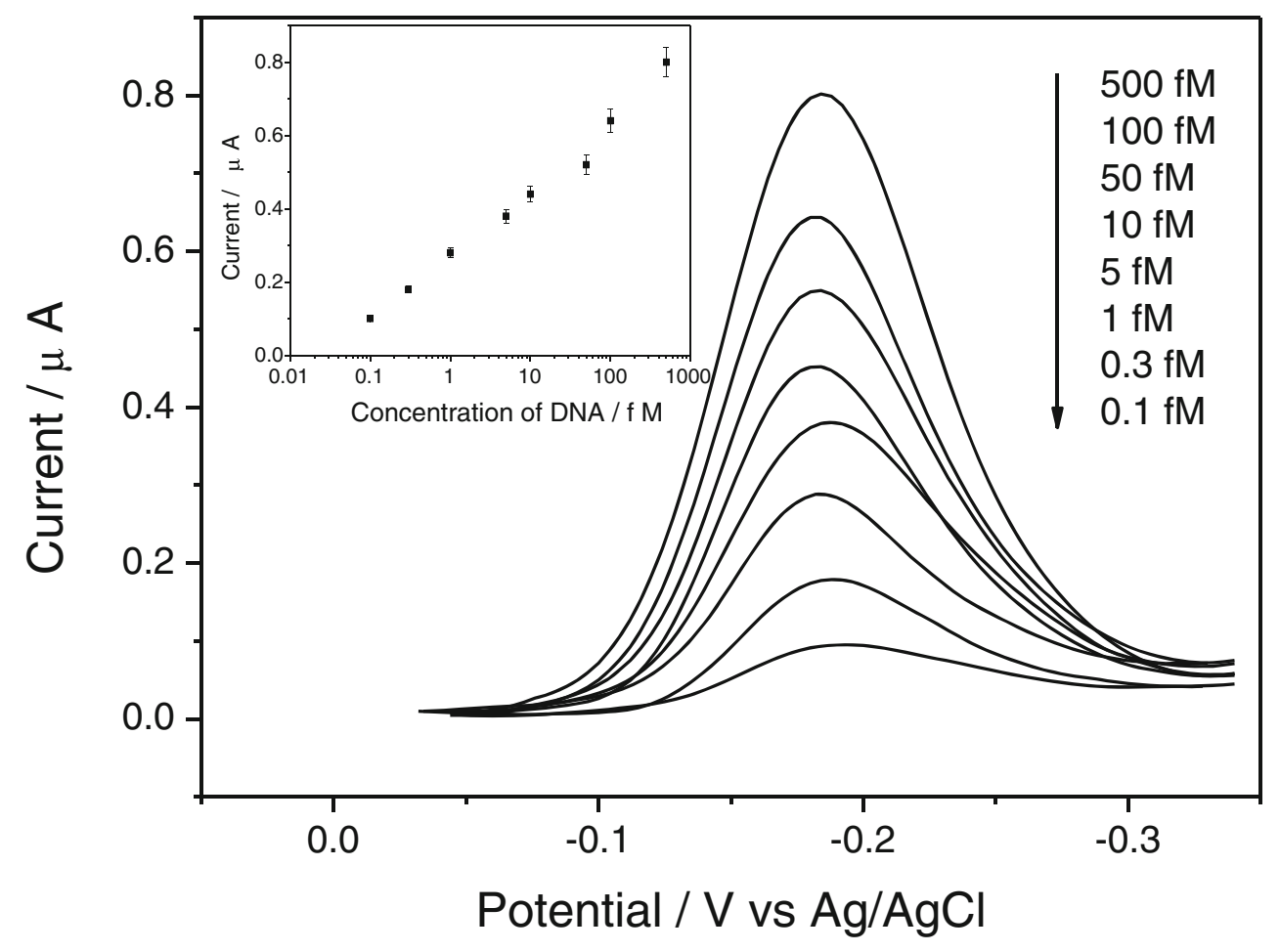


detections with six different sensors was $6.8 \%$, indicating that measurements using the DNA sensor are highly reproducible.

\section{Detection of sequence-selective hybridization}

The DNA sensor was exposed to noncomplementary DNA and single-base mismatch DNA to illustrate its selectivity. Almost no DPV peak was observed in the presence of noncomplementary target DNA (Fig. 6). This result demonstrates that the DNA sensor did not respond to the noncomplementary target DNA. Though the DNA sensors responded to the single-base mismatch DNA, the response was weaker than that of the complementary target DNA. The current increments were 0.38 and $0.44 \mu \mathrm{A}$ for the $10 \mathrm{fM}$ single-base mismatch and complementary target DNA, respectively, indicating that the mismatched target DNA can be distinguished from the complementary targets. These results demonstrate the selectivity of the current assay.

\section{Conclusion}

A signal-amplified sandwich-type electrochemical DNA biosensor for the detection of target DNA was developed. Thionine-capped AuNP/reporter DNA conjugates were prepared by attaching electroactive thionine to ssDNA protected AuNP surface. Relatively low detection limits were obtained because of the signal-amplification effect of thionine-capped AuNP/reporter DNA conjugates. Compared with other electrochemical sensors, our system exhibits two main advantages. First, the AuNPs were coated with reporter DNA, which increased the stability of AuNPs, and more thionine can adsorb to AuNPs surface. Second, a simplified detection procedure was used. Thionine-capped AuNP/reporter DNA conjugates were used directly to enhance the signal. This eliminates the need for further procedure such as enzymatic electroactive materials after the formation of a sandwich complex. We believe that our method would be valuable in electrochemical detection of DNA.

\begin{abstract}
Acknowledgments The authors gratefully acknowledge the financial support from the National Nature Science Foundation of China (Nos. 21175089 and 21027007), Program for Changjiang Scholars and Innovative Research Team in University (IRT 1070), and Creative Experimental Project of National Undergraduate Student (CX12022).
\end{abstract}

Open AccessThis article is distributed under the terms of the Creative Commons Attribution License which permits any use, distribution, and reproduction in any medium, provided the original author(s) and the source are credited.

\section{References}

1. Liu AL, Wang K, Weng SH, Lei Y, Lin LQ, Chen W, Lin XH, Chen YZ (2012) Development of electrochemical DNA biosensors. TrAC Trends Anal Chem 37:101-111

2. Luan QF, Xue Y, Yao X (2010) A simple hairpin DNA sensor for label-free detection of sub-attomole DNA target. Sensors Actuators B Chem 147:561-565

3. Zhang B, Liu BQ, Tang DP, Niessner R, Chen GN, Knopp D (2012) DNA-based hybridization chain reaction for amplified bioelectronic signal and ultrasensitive detection of proteins. Anal Chem 84:53925399

4. Su XD, Teh HF, Aung KMM, Zong Y, Gao ZQ (2008) Femtomol SPR detection of DNA-PNA hybridization with the assistance of DNAguided polyaniline deposition. Biosens Bioelectron 23:1715-1720

5. Huang YQ, Liu XF, Fan QL, Wang LH, Song SP, Wang LH, Fan CH, Huang W (2009) Tuning backbones and side-chains of cationic conjugated polymers for optical signal amplification of fluorescent DNA detection. Biosens Bioelectron 24:2973-2978

6. Sadik OA, Mwilu SK, Aluoch A (2010) Smart electrochemical biosensors: from advanced materials to ultrasensitive devices. Electrochim Acta 55:4287-4295

7. Yu FL, Li G, Qu B, Cao W (2010) Electrochemical detection of DNA hybridization based on signal DNA probe modified with $\mathrm{Au}$ and apoferritin nanoparticles. Biosens Bioelectron 26:1114-1117

8. Soreta TR, Henry OYF, O1Sullivan CK (2011) Electrode surface nanostructuring via nanoparticle electronucleation for signal enhancement in electrochemical genosensors. Biosens Bioelectron 26:39623966

9. Li W, Wu P, Zhang H, Cai CX (2012) Signal amplification of graphene oxide combining with restriction endonuclease for sitespecific determination of DNA methylation and assay of methyltransferase activity. Anal Chem 84:7583-7590

10. Li Y, Schluesener HJ, Xu S (2010) Gold nanoparticle-based biosensors. Gold Bull 43:29-41

11. Song YZ, Song Y, Zhong H (2011) Gold nanoparticle/double-walled carbon nanotube-modified glassy carbon electrode and its application. Gold Bull 44:107-111

12. Kerman K, Saito M, Morita Y, Takamura Y, Ozsoz M, Tamiya E (2004) Electrochemical coding of single-nucleotide polymorphisms by monobase-modified gold nanoparticles. Anal Chem 76:1877-1884

13. Li XM, Fu PY, Liu JM, Zhang SS (2010) Biosensor for multiplex detection of two DNA target sequences using enzyme-functionalized Au nanoparticles as signal amplification. Anal Chim Acta 673:133-138

14. Wang J, Li JH, Baca AJ, Hu JB, Zhou FM, Yan W, Pang DW (2003) Amplified voltammetric detection of DNA hybridization via oxidation of ferrocene caps on gold nanoparticle/streptavidin conjugates. Anal Chem 75:3941-3945

15. Zhu LM, Luo LQ, Wang ZX (2012) DNA electrochemical biosensor based on thionine-graphene nanocomposite. Biosens Bioelectron 35: $507-511$

16. Dohno C, Stemp EDA, Barton JK (2003) Fast back electron transfer prevents guanine damage by photoexcited thionine bound to DNA. J Am Chem Soc 125:9586-9587

17. Liu SN, Wu P, Li W, Zhang H, Cai CX (2011) Ultrasensitive and selective electrochemical identification of hepatitis $\mathrm{C}$ virus genotype $1 \mathrm{~b}$ based on specific endonuclease combined with gold nanoparticles signal amplification. Anal Chem 83:4752-4758

18. Wang JL, Munir A, Li ZH, Zhou HS (2010) Aptamer-AuNPs conjugates-accumulated methylene blue for the sensitive electrochemical immunoassay of protein. Talanta 81:63-67

19. Zhang XA, Teng YQ, Fu Y, Xu LL, Zhang SP, He B, Wang CG, Zhang W (2010) Lectin-based biosensor strategy for electrochemical assay of glycan expression on living cancer cells. Anal Chem 82: 9455-9460 
20. Mirkin CA, Letsinger RL, Mucic RC, Storhoff JJ (1996) A DNAbased method for rationally assembling nanoparticles into macroscopic materials. Nature 382:607-609

21. Wang J, Wang LH, Liu XF, Liang ZQ, Song SP, Li WX, Li GX, Fan CH (2007) A gold nanoparticle-based aptamer target binding readout for ATP assay. Adv Mater 19:3943-3946

22. Liu T, Zhao J, Zhang DM, Li GX (2010) Novel method to detect DNA methylation using gold nanoparticles coupled with enzymelinkage reactions. Anal Chem 82:229-233

23. Hurst SJ, Lytton-Jean AKR, Mirkin CA (2006) Maximizing DNA loading on a range of gold nanoparticle sizes. Anal Chem 78:8313-8318

24. Pei H, Li F, Wan Y, Wei M, Liu H, Su Y, Chen N, Huang Q, Fan C (2012) Designed diblock oligonucleotide for the synthesis of spatially isolated and highly hybridizable functionalization of DNA-gold nanoparticle nanoconjugates. J Am Chem Soc 134:11876-11879

25. Liu J, Yuan XQ, Gao Q, Qi HL, Zhang CX (2012) Ultrasensitive DNA detection based on coulometric measurement of enzymatic silver deposition on gold nanoparticle-modified screen-printed carbon electrode. Sensors Actuators B Chem 162:384-390

26. Das S, Kamat PV (1999) Can H-aggregates serve as light-harvesting antennae? Triplet-triplet energy transfer, between excited aggregates and monomer thionine in aersol-OT solutions. J Phys Chem B 103: 209-215

27. Li GJ, Liu LH, Qi XW, Guo YQ, Sun W, Li XL (2012) Development of a sensitive electrochemical DNA sensor by 4-aminothiophenol self-assembled on electrodeposited nanogold electrode coupled with Au nanoparticles labeled reporter ssDNA. Electrochim Acta 63:312317

28. Liu YH, Li HN, Chen W, Liu AL, Lin XH, Chen YZ (2013) Bovine serum albumin-based probe carrier platform for electrochemical DNA biosensing. Anal Chem 85:273-277

29. Hu KC, Lan DX, Li XM, Zhang SS (2008) Electrochemical DNA biosensor based on nanoporous gold electrode and multifunctional encoded DNA-Au bio bar codes. Anal Chem 80:9124-9130 